\title{
The Relationship among University Students' Trust, Self-Esteem, Satisfaction with Life and Social Media Use ${ }^{1}$
}

\author{
Ismail Acun
}

Assoc. Prof.., Eskisehir Osmangazi University, Turkey, iacun@ogu.edu.tr

The study is aimed at explaining the relationships among trust, self-esteem and satisfaction with life of university student with their social media use and some demographic variables. The demographic variables are; gender, socioeconomic status, grade point average (GPA) of students and their stated worldviews. The study employed a quantitative research approach. The subjects of the study were students of several social science departments in 12 different Turkish state universities located in several parts of Turkey. The total number of the students involved in the study was 2253 . The data was collected by a categorical variable form and 3 other scales developed for the research project. The scales were Likert type scales. Their reliability and dimensions are explained in detail in method section of the study. The data were analyzed through one-way-ANOVA. The main findings are; the frequency of social media use creates a difference in trust levels of university students. It is found out that a higher average of the grades means higher self-esteem among students. There is significant difference between genders in students' satisfaction with life.

Keywords: self-esteem, satisfaction with life, trust, social media, tertiary education

\section{INTRODUCTION}

While social media tools are rapidly impacting in people's lives, so do researcher try to understand the extent to which it affects people. Growing interest in research area also associated three important variables related to social media; self-esteem, trust and satisfaction with life (Steinfield et al, 2008). Social media networks gaining importance in playing a crucial role in democratic societies to function in modern societies. Many students have begun to use social networking more for academic fields. Although they are concerned about privacy and trust, students are still willing to use these networks (Kyei-Blankson \& Subramanian, 2016). Self-esteem, trust in human nature and

\footnotetext{
${ }^{1}$ The data for the study is drawn for the data collected for a TUBITAK Project numbered 114K190. I am grateful for TUBITAK and the scholars who was involved in certain parts of the project. An early version of the study was presented in ICES 2017, Antalya

Citation: Acun, I. (2020). The Relationship among University Students' Trust, Self-Esteem, Satisfaction with Life and Social Media Use. International Journal of Instruction, 13(1), 35-52. https://doi.org/10.29333/iji.2020.1313a
} 
satisfaction with life are the factors that became even more important after the social media began to affect human life very deeply. There are many researches that have produced a contrasting effect on the self-esteem and life-satisfaction of the internet. Some of them claim that the Internet cause loneliness for the people, and that it damages the social network that they have created in the physical life (Hofer \& Aubert, 2013). On the other hand, some researches have pointed out that the internet and social media is beneficial for democratic societies because of its flexible and multifunctional structure independent from time and space (Hofer \& Aubert, 2013). In both cases self-esteem, trust and satisfaction with life are important factors.

There are conflicting research findings on the relationship among self-esteem, satisfaction with life and social media usage among young people. A study of Metzler \& Herbert (2015) point that Facebook, a social media platform, highlighted the beneficial effect on self-esteem as a variable of the present research. The study displayed that overall adolescents' self-presentation on Facebook reflects their reported self-concept facets. That is, there is a positive association between adolescents' congruent selfpresentation and self-esteem. Contrary to the benefits of the Internet and social media to the lives of individuals, discussions continue on the negative reflections. Sahin (2015) found that social media addiction has negative effects on life satisfaction of university students. In other words, as the addiction on social media increases, life satisfaction of university students will decrease. In another study, it was revealed that internet and social media addiction led students to depression. Therefore, it is possible to say that there is a decrease in life satisfaction of students when it comes to social media usage. In addition, it was found out that students with high self-esteem use the internet less frequently and effectively. Moreover, it is suggested that these students are less likely to be depressed, and as a result their level of satisfaction with life is higher (Kircaburun, 2016).

\section{Social Media and Trust, Satisfaction with Life, Self-Esteem}

When the structure of democratic societies is analyzed, it is emphasized that one of the most basic indicators of the healthy functioning of these societies is trust. Trust is gaining importance both in the confidence that individuals have in respect of the other individuals who make up the society, and in the confidence, they have in the institutions of the democratic system. Trust is perhaps the most important concept in the functioning of social cohesion, economic efficiency and sound democracy (Newton, 2001; Newton \& Zmerli, 2011). Studies show that the relationship among trust, self-esteem, satisfaction with life and social media use are there to be examined for the foreseeable future.

Social media creates a unique and constant social address for individuals, thus enabling them to reach and re-do their connections for the individual without restriction in terms of spatial, temporal and social distance. It is also a functional tool for developing close relationships with social media by reminding individuals about the need to link through algorithms. In this context, individuals who share common ideas and ideas develop their common interests through social media (Greenhow \& Burton, 2011; Quinn, 2016). 
Trust is generally described as one's actions that make the person vulnerable to some other person(s) on the presupposition that the other will act positively. This happens in a social context. Individuals interact with each other in social relationships for mutual benefit. That is why, trust is a psychological state that guides individuals' actions based on past experiences and future expectations from other human beings (Korsgaard, 2018). Thus, it is an important variable to consider when researching about social media which is solely works for human interaction.

One can find definition of self-esteem as a person's self-evaluation of himself or herself, or one's judgment of self-worth (Branden, 1969; Zywica \& Danowski, 2008; Havi \& Samaha, 2017). The studies examining the link between self-esteem and social media use asserted that individuals having low level of self-esteem tend to use social media more frequently to improve self-image and self-esteem (Steinfield et al., 2008; Błachnio et al., 2016). Similar to trust, self-esteem is also rooted in interpersonal rejection and acceptance (Riker, 2017). Scholars attributed too much importance to self-esteem in understand a persons' psychology and well-being. Many negative outcomes were attributed to low level of self-esteem. However, researchers do not agree on the importance of the self-esteem as it was attributed before (Riker, 2017; Baumeister \& Vohs, 2018). Nevertheless, it is still an important variable alongside trust and satisfaction with life when researching university students' use of social media. Selfesteem is the essence of social experiences such as social acceptance, interpersonal characteristics, interpersonal behavior, relationship quality and relationship continuity (Cameron \& Granger, 2018). That is, it is an associated trait with constructs making human a social being. Cameron \& Granger (2018) conducted a meta-analysis of the relationship between self-esteem and five interpersonal traits in order to show the importance of self-esteem in understanding interpersonal relationships. The results indicated that the association between self-esteem and the majority of objective interpersonal indicators was small to moderate. Marino et al., (2018) conducted a comprehensive meta-analysis on problematic Facebook use. According to these results, there was a positive effect in favor of girls, a positive relationship was found between problematic Facebook use, online time spent and internet addiction. Moreover, problematic Facebook usage, time spent and internet addiction variables are negatively correlated with self-esteem. Problematic Facebook usage, neuroticism and responsibility were found to be most closely related to personality traits. Barucha (2018) also examined the extent to which social media plays a role in reducing well-being, dependent behavior and other harmful social effects. Social media usage patterns are categorized as threats to well-being because of the nature of online relationships.

Calvo, et al., (2018) explained the use of social networking sites in homeless individuals and the relationship between their use and self-esteem and life satisfaction levels. These results indicate that there is a high level of use of internet and social networking sites among these people, and even slightly higher than the other general population. The variables affecting the level of well-being are related to being in contact with social networking sites, especially with friends. Self-esteem plays a crucial role in adolescents school life (Mustapha \& Odediran, 2019). 
Satisfaction with live is used a general term to describe a person's general well-being and quality of live. A person's satisfaction with life is affected by many factors that are inevitable mingling with the person normal way of life (Veenhoven, 1996). Those factors can be age, gender, socio-economic status, sociocultural environment, personal construct and so on (Koker, 1991).

Satisfaction with life is crucial for a person to overcome ongoing obstacles and psychological well-being (Myers \& Diener, 1995). A body of research have been accumulated over the years about the relationship between satisfaction with life and social media use (Błachnio \& Przepiorka, 2018; Marino et al., 2018). Less attention was paid to university students' satisfaction with life, their social media use and academic performance. However, there recent research indicating that there is a positive relationship between university students' satisfaction with life and academic achievement (Ellison et al., 2007; Saha \& Karpinsky, 2018). In another study, Cattık \& Aksoy (2018) found that there was a strong and significant relationship among social support, self-efficacy and satisfaction with life as perceived by the families of children with developmental disability. They found that social support and self-efficacy variables had significant predictive power in explaining satisfaction with life. Hawi \& Samaha (2017) found that while social media addiction was negatively correlated with selfesteem, there was a positive correlation between self-confidence and satisfaction with life. Moreover, the results of the path analysis showed that self-esteem mediated the impact of social media addiction on life satisfaction. Blachnio \&Przepiorka (2019) tested the relationship between smartphone embedding, self-esteem, loneliness and satisfaction with life. The low level of loneliness is also a predictor of Facebook login, which is also in turn a predictor of loneliness.

Trust, self-esteem and satisfaction were treated as dependent variable in a series of oneway ANOVA with categorical variables of gender, academic achievement (GPA), socioeconomic status and frequency of social media use and worldviews of university students.

Thus, the research questions formulated to understand the relationship among university students' social media use, trust to human nature, self-esteem and satisfaction with life with the categorical variables mentioned above:

Is there any differentiation in variance in university students' level of trust to human nature according to gender, GPA, socioeconomic status, frequency of social media use and worldviews?

Is there any differentiation in variance in university students' level of self-esteem according to gender, GPA, socioeconomic status, frequency of social media use and worldviews?

Is there any differentiation in variance in university students' level of satisfaction with life according to gender, GPA, socioeconomic status, frequency of social media use and worldviews? 


\section{METHOD}

\section{Model}

The study employs a survey research model. In order to gather a set of data form a good representative sample of the university students studying social science departments in Turkish state universities a stratified sampling method was tried to be used. To collect data from the intended sample of the population, different data gathering tools were developed and used for the research. The data gathering tools were; a demographic data sheet was designed for the independent variable such as world views of the students, grade point averages (GPA), gender, types of social media use, the frequency of social media use and socioeconomic status questions to develop socioeconomic index. For the dependent variables, 3 different Likert type scales of self-esteem, trust and satisfaction with life were developed.

\section{Population and Sampling}

The data was collected from 2253 university students. A stratified sampling method was tried to be employed for the study across Turkey. However, among randomly selected universities from 26 regions in Turkey only twelve faculties responded positively. Thus, 2253 students were involved in the study with the varying response rates from each university. One should note that 'sample of the study' does not reflect the intended representation of the population under investigation. Therefore, the results cannot be generalized. The universities are Eskisehir Osmangazi University, Anadolu University, Hacettepe University, Gazi University, Karadeniz Technical University, Karabuk University, Adıyaman University, Ataturk University, Dumlupınar University, Usak University, Necmettin Erbakan University and Istanbul University.

Features of the sample: students are all 2. 3. and $4^{\text {th }}$ year students studying letter faculties of state universities. The gender ratio is nearly $70 \%-30 \%$ in favor of female gender.

\section{Data gathering tools}

Demographic data collection tool included many items to create socio-economic status index. Demographic data sheet also designed to collect data on; grand point average of students, gender, and membership to any NGOs based in or out of university campus, political views of the students, type of social media use and frequency of social media use. Self-esteem, trust and satisfaction with life scales were developed for the study. The scales are all included choices of 0 to 9 ( 0 means none/never 9 means completely/all the time) for each item in a Likert type of selection.

\section{Validity and Reliability}

A pool of items was developed for each scale drawn from the literature. Then, validity check procedures were completed by utilizing expert opinions for each scale. A pilot study was carried out for each of the scales for both validity and reliability. In order to 
test whether the scales are suited for factor analysis Kaiser-Meyer-Olkin test was run. Cronbach's Alpha was used to test the scales' reliability.

There were several self-esteem studies used for the development of the items in the scale for the pilot study (Branden, 1969; Greenhow \& Burton, 2011; Havi \& Samaha, 2017). Self-esteem scale's items all had choices ranging from 0 to 9 in a Likert type for students to mark. Self-esteem scale had values, $(\mathrm{KMO}=.84, \mathrm{p}<.001 ; .80$ Cronbach's Alpha; total variance explained $=56 \%$ ): The factor analysis shows that the instrument contains five items and one factor.

There were several trust studies used for the development of the items in the scale for the pilot study (Newton, 2001; Greenhow \& Burton, 2011; Riker, 2017; Havi \& Samaha, 2017). Trust scale's items all had choices ranging from 0 to 9 in a Likert type for students to mark. Trust scale had values, $(\mathrm{KMO}=.75 \mathrm{p}<.001 ; .88$ Cronbach's Alpha; total variance explained $74 \%$ ): The factor analysis shows that the instrument contains four items and one factor.

There were several satisfactions with life studies used for the development of the items in the scale for the pilot study (Köker, 1991; Saha \& Karpinsky, 2018). Satisfaction with life scale's items all had choices ranging from 0 to 9 in a Likert type for students to mark. Satisfaction with life scale had values $(\mathrm{KMO}=.87 \mathrm{p}<.001 ; .87$ Cronbach's Alpha; total variance explained $66 \%$ o): The factor analysis shows that the instrument contains five items and one factor.

\section{Data gathering procedures}

After finalizing the scales, items were transferred to an optical form for the university students to mark and write their choices. The data were collected by the research team face-to-face in the classrooms of the universities mentioned above. Having obtained legal permissions and ethical comity report, it was only necessary to state the students that it is completely voluntary to join in the research. Anonymity and all other ethical issues were addressed properly.

\section{Analysis}

One-way-ANOVA was used to explain the relationship among categorical data and data collected through the three scales mentioned.

\section{FINDINGS}

Statistically significant relationships found in one-way-ANOVOs are reported here throughout the findings.

\section{Self-esteem}

Descriptive findings of the self-esteem instrument showed that the average of university students' self-esteem $(\bar{x}=6.46)$ was greater than the median. 
Table 1

Self-Esteem

\begin{tabular}{lll}
\hline & $\overline{\mathrm{X}}$ & $\mathrm{SS}$ \\
\hline Self esteem & 6.46 & 1.77 \\
\hline
\end{tabular}

In order to test whether gender is an important factor in the possible differentiation in students' self-esteem level, independent group t-test was run. The result shows that gender is not a determinant variable in differentiation of students' self-esteem.

One-way analysis of variance (ANOVA) was conducted to determine whether university students' academic grade averages were a decisive factor in their self-esteem. The results are presented in Table 2. The one-way ANOVA result showed that the academic grade average was a determining variable for self-esteem $\left(\mathrm{F}_{(4.2221)}=8.970 ; \mathrm{p}<.001\right)$.

Table 2

Analysis of Variance between GPA and Self-Esteem (ANOVA)

\begin{tabular}{llllll}
\hline Source of variance & SS & SD & MS & F & p \\
\hline Between Groups & 110.91 & 4 & 27.73 & 8.97 & .000 \\
Within Groups & 6865.33 & 2221 & 3.09 & & \\
Total & 6976.24 & 2225 & & & \\
\hline
\end{tabular}

Table 3 shows multiple comparisons among the groups according to the grade point average. Findings show that a higher average of the grades means higher self-esteem, and shows that the group with the highest level of self-esteem is the group with an average of 3.50-4.00.

Table 3

Multiple Comparisons of University Students' Self-Esteem by GPA

\begin{tabular}{lclll}
\hline & Groups (GPD) & $\overline{\mathrm{X}}$ & SS & 'statistically significant from \\
\hline 1 & Below 2 & 5.82 & 2.07 & $3^{* *}, 4^{* * *}, 5^{* *}$ \\
2 & $2.00-2.49$ & 6.27 & 1.79 & $4^{* *}$ \\
3 & $2.50-2.99$ & 6.47 & 1.68 & $1^{* *}$ \\
4 & $3.00-3.49$ & 6.69 & 1.78 & $1^{* * *}, 2^{* *}$ \\
5 & $3.50-4.00$ & 6.76 & 1.73 & $1^{* *}$ \\
\hline \multicolumn{2}{l}{$\mathrm{p}<* .05 * * .01 * * * .001$} & &
\end{tabular}

One-way analysis of variance (ANOVA) was conducted to determine whether the socioeconomic status of university students (SES) was a decisive factor in their selfesteem. The one-way ANOVA outcome showed that the socioeconomic status of university students was not a determining variable for their level of self-esteem. According to this finding, the self-esteem of the students does not change according to socioeconomic levels.

One-way analysis of variance (ANOVA) was conducted to determine whether university students' worldview (political, religious etc. affiliations) caused any differentiation in their level of self-esteem. According to the findings, it can be said that the students' selfesteem did not differ from each other according to their held worldview. 


\section{Trust in human nature}

Descriptive findings related to the general trust measurement tool showed that university students' positive tendency average for confidence in human nature is lower than the median $(\bar{x}=3.33)$. This means that the students' confidence in human nature is fairly low.

Table 4

Trust in Human Nature

\begin{tabular}{lll}
\hline & $\overline{\mathrm{X}}$ & SS \\
\hline Trust & 3.33 & 2.49 \\
\hline
\end{tabular}

Independent group t-test was run in order to test whether the gender of university students differentiated the positive attitude towards the human nature of trust (Table 5). Results were statistically significant $(\mathrm{t}=-2.04, \mathrm{p}<.05)$. The positive tendency $(\overline{\mathrm{x}}=3.48)$ of male students about their confidence in human nature $(\overline{\mathrm{X}}=3.48)$ is significantly higher than that of female students with positive attitudes toward human nature $(\overline{\mathbf{x}}=$ 3.24).

Table 5

Independent Group T-Test

\begin{tabular}{lllllll}
\hline Group & $\mathrm{n}$ & $\overline{\mathrm{x}}$ & $\mathrm{SS}$ & $\mathrm{Sd}$ & $\mathrm{t}$ & $\mathrm{p}<$ \\
\hline Female & 1540 & 3.24 & 2.39 & \multirow{2}{*}{1137.78} & -2.04 & .042 \\
Male & 665 & 3.48 & 2.69 & & & \\
\hline
\end{tabular}

One-way analysis of variance (ANOVA) was conducted to determine whether the academic grade average of university students was a decisive variable for the positive tendency towards confidence in human nature. As can be seen from Table 6, one-factor ANOVA showed that the average academic grade average was a decisive variable for the positive tendency towards trust in human nature $\left(\mathrm{F}_{(4.2220)}=10.99 ; \mathrm{p}<.001\right)$.

Table 6

Analysis of Variance in Level of Students' Trust in Human Nature According to Their GPA

\begin{tabular}{llllll}
\hline Source of variance & SS & SD & MS & F & p $<~$ \\
\hline Between Groups & 267.57 & 4 & 66.89 & & \\
Within Groups & 13511.71 & 2220 & 6.09 & 10.99 & .000 \\
Total & 13779.28 & 2224 & & & \\
\hline
\end{tabular}

Table 7 shows multiple comparisons among the groups according to the grade point average. Comparing the students' confidence to human nature according to the grade point average of the university students, the tendency to trust in human nature ( $\bar{x}=2.36)$ of the students with below average 2 seems to be lower than that of the students in all other groups. Students with a GPA of 3.00-3.49 had a significantly higher tendency to trust in human nature $(\overline{\mathrm{x}}=3.70)$, significantly higher than GPA of 2.00-2.49 $(\overline{\mathrm{x}}=3.09)$ and 2.50-2.99 $(\overline{\mathrm{x}}=3.28)$. The highest students' tendency to trust in human nature $(\overline{\mathrm{x}}=$ 3.91) was in the group with the highest-grade average (range 3.50-4.00). It was significantly higher than that of the group with the lowest grade average (2.00 and 
below). In this case, it can be said that there is a positive relationship between the grade average and the positive tendency regarding trust in human nature.

Table 7

The Multiple Comparison of Students' Level of Trust in Human Nature According to Their GPA

\begin{tabular}{lllll}
\hline & Groups & $\square$ & SS & 'statistically significant from \\
\hline 1 & Below 2 & 2.36 & 2.22 & $2 *, 3 * * *, 4 * * *, 5 * * *$ \\
2 & $2.00-2.49$ & 3.09 & 2.45 & $1 *, 4 * * *$ \\
3 & $2.50-2.99$ & 3.28 & 2.45 & $1 * * *, 4 *$ \\
4 & $3.00-3.49$ & 3.70 & 2.50 & $1 * * *, 2 * * *, 3 *$ \\
5 & $3.50-4.00$ & 3.91 & 2.76 & $1 * * *$ \\
\hline $\mathrm{p}<* .05 * * .01 * * * .001$ & &
\end{tabular}

One-way ANOVA was conducted to determine whether the socioeconomic levels of university students (SES) were a determining variable in the positive tendencies towards trust in human nature. The results of the analysis revealed that SES was not a determining variable $\left(\mathrm{F}_{(4.2241)}=1.07 ; \mathrm{p}=.370\right)$.

Similarly, variance analysis aimed at testing whether university students' worldviews make a difference $\left(\mathrm{F}_{(8.2073)}=1.83 ; \mathrm{p}=.067\right)$ was run. There was no statistically significant difference.

One-way ANOVA was performed to determine whether the students' level of trust in the human nature varied according to the levels of their use of social media. As a result of one-way ANOVA, it is seen that the average of level of trust in the nature of the students is different according to the frequency of social media usage $\left(\mathrm{F}_{(4.2241)}=6.59 ; \mathrm{p}<.001\right)$. The findings of the variance analysis made in Table 8 are presented.

Table 8

Analysis of Variance in Level of Students' Trust in Human Nature According to Students' use of Social Media

\begin{tabular}{llllll}
\hline Source of variance & SS & SD & MS & F & p $<$ \\
\hline Between Groups & 161.92 & 4 & 40.48 & & \\
Within Groups & 13765.29 & 2241 & 6.14 & 6.59 & .000 \\
Total & 13927.21 & 2245 & & & \\
\hline
\end{tabular}

Table 9 shows multiple comparisons among the groups according to their use of social media frequency. According to the results of multiple comparison tests; university students' level of trust in human nature who use social media rarely are significantly higher than those whose use of social media frequency is higher $(\bar{x}=3.59)$, fewer $(\bar{x}=$ 3.20) and much $(\overline{\mathrm{X}}=2.85)$. 
Table 9

The Multiple Comparison of Students' Level of Trust in Human Nature According to Their' use of Social Media Frequency

\begin{tabular}{lllll}
\hline \multicolumn{1}{l}{ Groups } & $\overline{\mathrm{X}}$ & $\mathrm{SS}$ & statistically significant from \\
\hline 1 & Never use & 3.48 & 2.73 & \\
2 & Rarely use & 3.59 & 2.48 & $3 *, 4 * * *$ \\
3 & Occasionally use & 3.20 & 2.47 & $2 *$, \\
4 & A lot use & 2.85 & 2.36 & $2 * * *$ \\
5 & Too much use & 3.06 & 2.77 & \\
\hline $\mathrm{p}<* .05 * * .01 * * * .001$ & & &
\end{tabular}

\section{Satisfaction with life}

It is seen that the satisfaction with life averages $(\bar{x}=4.40)$ of university students are not too high or low rather it is in the middle when the descriptive statistics related to collected data with the satisfaction with life measuring tool are examined (see Table 10).

Table 10

Satisfaction with Life

\begin{tabular}{lll}
\hline & $\overline{\mathrm{X}}$ & SS \\
\hline Satisfaction with life & 4.40 & 2.21 \\
\hline
\end{tabular}

Independent sample group t-test was conducted to determine whether the satisfaction with life level of university students varied according to gender (Table 11). According to the test results, the average satisfaction with life level of university students differ significantly by gender $(\mathrm{t}=3.23 ; \mathrm{p}<.01)$. The average satisfaction with life level of female students $(\bar{x}=4.51)$ is significantly higher than that of male students $(\bar{x}=4.18)$.

Table 11

Independent Sample Group T-Test for Satisfaction with Life According to Gender

\begin{tabular}{lllllll}
\hline Group & $\mathrm{n}$ & $\overline{\mathrm{x}}$ & $\mathrm{SS}$ & $\mathrm{Sd}$ & $\mathrm{t}$ & $\mathrm{p}<$ \\
\hline Female & 1540 & 4.51 & 2.21 & 2203 & 3.23 & .001 \\
Male & 665 & 4.18 & 2.20 & & & \\
\hline
\end{tabular}

One-way analysis of variance (ANOVA) was performed to determine whether the average level of satisfaction with life of university students varied according to the grade average points (Table 12). According to the test results, satisfaction with life level of university students differ statistically according to grade average points $\left(\mathrm{F}_{(4.2220)}=5.46\right.$; $\mathrm{p}<.01)$.

Table 12

Variance between Satisfaction with Life and GPA

\begin{tabular}{llllll}
\hline Source of variance & SS & SD & MS & F & p $<$ \\
\hline Between Groups & 105.96 & 4 & 26.49 & & \\
Within Groups & 10774.22 & 2220 & 4.85 & 5.46 & .000 \\
Total & 10880.18 & 2224 & & & \\
\hline
\end{tabular}

When the satisfaction with life averages were compared according to the grade point average groups (Table 13), the satisfaction with life averages $(\overline{\mathrm{x}}=4.63)$ of the students 
with grade point average of 3.00-3.49, is statistically higher than the university students with 2.00 or lower grade average $(\overline{\mathrm{x}}=3.94)$, and the students with a $2.00-2.49$ grade point average $(\bar{x}=4.15)$.

Table 13

Multiple Comparison of Satisfaction with Life Average of Students with Their GPA

\begin{tabular}{lllll}
\hline & Groups & $\overline{\mathrm{X}}$ & $\mathrm{SS}$ & statistically significant from \\
\hline 1 & Below 2.00 & 3.94 & 2.17 & $4^{*}$ \\
2 & $2.00-2.49$ & 4.15 & 2.29 & $4 *$ \\
3 & $2.50-2.99$ & 4.42 & 2.21 & \\
4 & $3.00-3.49$ & 4.63 & 2.14 & $1^{*}, 2^{*}$ \\
5 & $3.50-4.00$ & 4.80 & 2.03 & \\
\hline p $<* .05 * * .01 * * .001$ & &
\end{tabular}

According to the one-way ANOVA, the satisfaction with life averages of the students do not differ according to the socioeconomic levels $\left(\mathrm{F}_{(4.2241)}=1.82 ; \mathrm{p}>.05\right)$.

A one-way analysis of variance (ANOVA) was conducted to determine whether the satisfaction with life of university students varied according to their held worldviews (Table 14). According to the results of the one-way ANOVA test, the satisfaction with life averages of the university students differ according to their held worldviews ( $F$ $(8.2073)=6.85 ; \mathrm{p}<.01)$.

Table 14

Analysis of Variance Held Worldview and Satisfaction with Life

\begin{tabular}{llllll}
\hline Source of variance & SS & SD & MS & F & p $<$ \\
\hline Between Groups & 262.92 & 8 & 32.87 & & \\
Within Groups & 9941.18 & 2073 & 4.80 & 6.85 & .000 \\
Total & 10204.09 & 2081 & & & \\
\hline
\end{tabular}

Looking at multiple comparisons (Table 15), students who defined themselves as Marxist / communist / socialist / atheist have lower satisfaction with life average $(\overline{\mathrm{x}}=$ 3.79), than the students who defined themselves as conservative / religious $(\bar{x}=4.79)$, Kemalist/nationalist/democrat $(\bar{x}=4.46)$ and Islamist $(\bar{x}=4.73)$. The satisfaction with life average of students who define themselves as apolitical $(\overline{\mathrm{x}}=3.77)$ is significantly lower than the satisfaction with life average $(\bar{x}=4.79)$ of students who define themselves as conservative / religious. 
Table 15

Multiple Comparison of Students' Satisfaction with Life Averages and Worldviews

\begin{tabular}{lllll}
\hline & Groups & $\overline{\mathrm{X}}$ & SS & statistically significant from \\
\hline 1 & Conservative_religious & 4.79 & 2.19 & $4^{* * *}, 9^{*}$ \\
2 & Liberal_humanist & 4.66 & 2.05 & \\
3 & Nationalist & 4.49 & 2.14 & \\
4 & Marxist_Communist_atheist & 3.79 & 2.26 & $1^{* * *}, 3^{*}, 6^{*}, 8^{*}$ \\
5 & Anarchist & 3.50 & 2.30 & \\
6 & Kemalist_nationalist_social democrat & 4.46 & 2.12 & $4^{*}$ \\
7 & Ultranationalist & 4.67 & 2.30 & \\
8 & Islamist & 4.73 & 2.37 & $4^{*}$ \\
9 & Apolitical & 3.77 & 2.29 & $1^{*}$ \\
\hline p & *.05 * $^{*} .01 * * * .001$ & & &
\end{tabular}

According to the one-way ANOVA results, the satisfaction with life averages of students do not different according to the frequency of social media usage $\left(\mathrm{F}_{(4.2241)}: 0,611 ; \mathrm{p}>\right.$ $.05)$.

\section{DISCUSSION}

Self-esteem, satisfaction with life and trust for human beings have been subject to some attention from the researchers dealing with issues surrounding social media, social capital, education and democratic citizenship. There is sound the theoretical basis for the interrelationship of the variable mentioned above. Indeed, as noted above, selfesteem has emerged from findings as being a significant variable in university students' use of social media frequency and other categorical variables such as gender, SES, worldview and GPA.

The most notable finding in this regard is the relationship between students' grades point averages and self-esteem. Findings show that a higher-grade point average means a higher level of self-esteem. The highest level of self-esteem is found among the student group which has an average of 3.50-4.00. Most previous research revealed that as academic performance increases, self-esteem ascends or vice versa (Erdinc \& Balk1s (2018) uncovered that academic performance has direct and interactive effects on selfesteem. Topcu \& Leana-Tascilar (2018) also found significant relationships between self-esteem, motivation and success. In their regression analysis, especially self-esteem in fourth grade and academic self-esteem in fifth grade students were found to be predictive of academic achievement. Similarly, Asakereh \& Yousofi (2018) also revealed significant positive relationships between general self-efficacy, self-esteem and academic achievement of Iranian foreign language teacher students. In addition, they discovered that self-esteem was one of the strongest predictors of academic achievement. These research on the association the self-esteem and students' grade, academic success, academic performance or achievements support the present result. Self-efficacy and motivation like self-esteem are affective constructs. As noted above, they are intensely related with each other. Many actions, ideas or thoughts are triggered and resulted from our affective traits such as emotions, feelings, values, beliefs etc. Any 
person with positive evaluation of himself or herself approaches positively, and caringly his or environment, the animal, the nature, and the people.

The result shows also that gender is not a determinant variable in differentiation of students' self-esteem. Contrary to the finding of this research, there are some research found that there is significant differentiation between self-esteem and gender. They found that men's self-esteem was higher than that of women (Gregg et al., 2016; Collison et al., 2016).

The findings of the analysis of the data obtained from the trust in human nature. Here, the grade point average is also an important factor in the individuals' trust in human nature. Students with a high average GPA are more inclined to trust in human nature. This can be explained by the fact that students with highest GPA are in a good position (specifically successful) in the context of their life experiences and the status they are in, and that they do not constitute a reason to create distrust in human nature in general. A study of Romero \& Gonzalez (2016) suggested that students with a higher level in confidence have higher academic achievement. As mentioned above in literature, like self-esteem, trust creates ground on interpersonal interaction and personal experiences (Riker, 2017; Korsgaard, 2018). If any person has positive trust and confidence in any event, he or she will have a higher chance of being successful in that particular area of life experience.

A similar situation was found in the analysis of data obtained through satisfaction with life measurement. The students with high GPA are more satisfied with their life then the students with average and low level of GPA.

The most important finding about satisfaction with life comes from the differences in satisfaction with life according to the students' worldviews. The average satisfaction with life of students who define themselves as Marxist / communist / socialist / atheist seems to be significantly lower than the average of students who define themselves as conservative / religious, nationalist, Kemalist / nationalist / social democrat and Islamist. The average satisfaction with life of students who define themselves as apolitical is also significantly lower than the satisfaction with life of students who define themselves as conservative / religious. It is understandable that students who define themselves as conservative/religious are very happy with a consecutive Justice and Development Party (AKP is a religion oriented conservative party)' rule of Turkey for nearly 17 years. Considering the age of the students, they do not know any other ruling party in their entire lives. Students in the worldview that exist in the people who form the basis of the Justice and Development Party constitute the happiest group due to the spiritual and / or material means that the system has presented to them.

Those students who define their worldview as one of the extreme political groups in Turkey such as Marxist, Atheist and Socialist etc. do not rip the benefit of political power and politicians. On the contrary they feel more and more outsiders of the political and social system. In the period of the AKP, which has a continuous and long-term government practice with an Islamist (at least religious) rhetoric beyond classical 
conservatism, the satisfaction with life of these group of students, who have spent almost all of their lives, will be understandably lower than those of the system.

There is no causal relationship between social media usage intentions and frequency and satisfaction with life, human nature trust and satisfaction with life. Even though social media addiction, which is a concept representing the excessive use of the Internet, does not constitute the main focus of this study, social media addiction and self-esteem explain $20 \%$ of daily internet use people (Kircaburun, 2016). In a similar study, it was found that there is a negative relationship between life satisfaction of university students and social media addiction. According to this result, as students' dependence on social media increases, life satisfaction decreases (Şahin, 2017). To put it clearly here, the dependent variables of the research, such as self-esteem, trust, life satisfaction, seem to be limited when we try to explain only the frequency of internet usage parameter when dealing with social media. It does not mean that the frequency of Internet use has no effect student's social media usage. It would be more accurate to explain the dependent variables of the research together with the factors affecting the Internet and its use.

\section{CONCLUSION}

In present study, it is aimed at explaining the relationships among trust, self-esteem and satisfaction with life of university student with their social media use and some demographic variables. The results were clarified respectively suitable to research questions. The first result shows that gender is not a determinant variable in differentiation of students' self-esteem. As mentioned in discussion part, this result is not in line with other research findings. It can be concluded that the gender issue has to be resolved in relationship social media usage of university students.

It is found that a higher average of the grades means higher self-esteem, and shows that the group with the highest level of self-esteem is the group with an average of 3.50-4.00. Moreover, according to the findings, it can be said that the students' self-esteem did not differ from each other according to their held worldview.

The positive tendency of male students about their confidence in human nature is significantly higher than that of female students with positive attitudes toward human nature. The results revealed that the average academic grade average was a decisive variable for the positive tendency towards trust in human nature $(\mathrm{F}(4.2220)=10.99 ; \mathrm{p}$ $<.001)$. The tendency to trust in human nature of the students with below average 2 seems to be lower than that of the students in all other groups. Students with a GPA of 3.00-3.49 had a significantly higher tendency to trust in human nature, significantly higher than GPA of 2.00-2.49 and 2.50-2.99. The highest students' tendency to trust in human nature was in the group with the highest-grade average. It was significantly higher than that of the group with the lowest grade average (2.00 and below). In this case, it can be said that there is a positive relationship between the grade average points and the positive tendency regarding trust in human nature.

Similarly, the study aimed at testing whether university students' worldviews make a difference, and an evidence was reached that there was no statistically significant difference. It is seen that the average of level of trust in the nature of the students is 
different according to the frequency of social media usage. Furthermore, according to the results of multiple comparison tests; university students' level of trust in human nature who use social media rarely are significantly higher than those whose use of social media frequency is higher, fewer and much.

For the test results, the average satisfaction with life level of university students differ significantly by gender. The average satisfaction with life level of female students is significantly higher than that of male students.

In the study, it was also examined to determine whether the average level of satisfaction with life of university students varied according to the grade average points. According to the test results, satisfaction with life level of university students differ statistically according to grade average points.

We tried to determine whether the satisfaction with life of university students varied according to their held worldviews. The satisfaction with life averages of the university students differ according to their held worldviews. Looking at multiple comparisons, students who defined themselves as Marxist / communist / socialist / atheist have lower satisfaction with life average, than the students who defined themselves as conservative / religious, Kemalist/nationalist/democrat and Islamist. The satisfaction with life average of students who define themselves as apolitical is significantly lower than the satisfaction with life average of students who define themselves as conservative / religious.

\section{SUGGESTIONS}

In the light of the findings two suggestion can be made for research and education;

Although, it was started with good intentions to collect data from a sample that is better representative of the population. As explained in the method section, it was not possible to work with a student population that matched the layered sample selection technique with justified tools. It is desirable to work with a sample selected by cluster sampling method.

Contrary to popular belief in society, the majority of students do not use social media very often. However, considering the usage purposes of users, entertainment, spending time and socialization are important places. For purposes of use, educational activities may be organized earlier in the year to raise awareness about the use of students for more meaningful purposes beyond time killing.

\section{REFERENCES}

Asakereh, A., \& Yousofi, N. (2018). Reflective thinking, self-efficacy, self-esteem and academic achievement of Iranian EFL students. Int. J. of Edu. Psychology, 7(1), 68-89.

Baumeister, R. F., \& Vohs, K. D. (2018). Revisiting our reappraisal of the (surprisingly few) benefits of high self-esteem. Perspectives on Psychological Sci., 13(2), 137-140.

Bharucha, J. (2018). Social network use and youth well-being: a study in India. Safer Communities, 17(2), 119-131. 
Blachnio, A., \& Przepiorka, A. (2019). Be aware! If you start using Facebook problematically, you will feel lonely: Phubbing, loneliness, self-esteem, and Facebook intrusion. A cross-sectional study. Social Science Computer Review, 37(2), 1-9.

Błachnio, A., Przepiorka, A., \& Rudnicka, P. (2016). Narcissism and self-esteem as predictors of dimensions of Facebook use. Pers. and Indiv. Differences, 90, 296-301.

Branden, N. (1969). Six pillars of self-esteem. Retrieved from http://www.nathanielbranden.com/on-self-esteem.

Calvo, F., Carbonell, X., Turro, O., \& Giralt, C. (2018). Connected in the street: The relation between online social networks, self-esteem and satisfaction with life among individuals experiencing homelessness. Aloma, 36(1), 21-28.

Cameron, J. J., \& Granger, S. (2018). Does self-esteem have an interpersonal imprint beyond self-reports? A meta-analysis of self-esteem and objective interpersonal indicators. Personality and Social Psychology Review, 23(1), 73-102.

Cattık, M., \& Aksoy, V. (2018). An examination of the relations among social support, self-efficacy and life satisfaction in parents of children with developmental disabilities. Education and Science, 43(195), 65-77.

Collison, D., Banbury, S., \& Lusher, J. (2016). Relationships between age, sex, selfesteem and attitudes towards alcohol use amongst university students. Journal of Alcohol and Drug Education, 60(2), 16-34.

Duru, E. \& Balk1s, M. (2017). Procrastination, self-esteem, academic performance and well-being: A moderated mediation model. Int. J. of Edu. Psychology, 6(2), 97-119.

Ellison, N. B., Steinfield, C., \& Lampe, C. (2007). The benefits of Facebook "friends:" social capital and college students' use of online social network sites. Journal of Computer-Mediated Communication, 12, 1143-1168.

Greenhow, C., \& Burton, L. (2011). Help from my "friends": Social capital in the social network sites of low-income students. J. of Edu. Computing Research, 45, 223-245.

Gregg, D. H., Somers, C. L., Pernice-Duca, F., \& Van Dale, K. G. (2016). Teasing experiences and risk-taking: Gender and self-esteem as moderator and mediator. Journal of School Violence, 15(3), 365-385.

Havi, N. S., \& Samaha, M. (2017). The relations among social media addiction, selfesteem and life satisfaction among university students. Social Science Computer Review, 35(5), 576-586.

Hofer, M., \& Aubert, V. (2013). Perceived bridging and bonding social capital on Twitter: Differentiating between followers and followers. Computers in Human Behavior, 29, 2134-2142.

Kircaburun, K. (2016). Self-Esteem, daily internet use and social media addiction as predictors of depression among Turkish adolescents. J. of Edu. and Pra., 7(24), 64-72. 
Koker, S. (1991). The comparison of level of satisfaction with life of normal people and people with problems (Unpublished master's thesis). Ankara University, Ankara.

Korsgaard, M. A. (2018). Reciprocal trust. In R. H. Searle, A. M. I. Nienaber, S. B. Sitkin (Eds.), The Routledge companion to trust (pp. 14-29). London: Taylor \& Francis.

Kyei-Blankson, L., Iyer, K. S., \& Subramanian, L. (2016). Social networking sites: College students' patterns of use and concerns for privacy and trust by gender, ethnicity, and employment status. International J. of Inf. and Com. Tech. Edu., 12(4), 62-75.

Marino, C., Gini, G., Vieno, A. \& Spada, M. M. (2018). A comprehensive meta-analysis on problematic Facebook use. Computers in Human Behavior, 83, 262-277.

Metzler, A., \& Scheithauer, H. (2015). Adolescent self-presentation on Facebook and its impact on self-esteem. International J. of Developmental Science, 9(3-4), 135-145.

Mustapha, M. L. A., \& Odediran, D. (2019). Impact of parental separation on selfesteem of in-school adolescents in Nigeria. Int. J. of Instruction, 12(1), 1281-1298.

Myers, D. G., \& Diener, E. (1995). Who is happy? Psychological Science, 6(1), 10-19.

Newton, K., \& Zmerli, S. (2011). Three forms of social trust and their association. European Political Science Review, 3(2), 169-200.

Newton, K. (2001). Trust, social capital, civil society and democracy. International Political Science Review, 22(2), 201-214.

Park, S. Y., \& Baek, Y. M. (2018). Two faces of social comparison on Facebook: The interplay between social comparison orientation, emotions and psychological wellbeing. Computers in Human Behavior, 79, 83-93.

Quinn, K. (2016). Contextual social capital: Linking the contexts of social media use to its outcomes. Information, Communication \& Society, 19(5), 582-600.

Riker, W. H. (2017). The nature of trust. In J. T. Tedeschi (Ed.), Social power and political influence (pp. 63-81). London: Routledge.

Saha, N., \& Karpinsky, A. C. (2018). The influence of social media on international students' global life satisfaction and academic performance. In M. Khrosrow-Pour (Ed.), Student engagement and participation: Concepts, methodologies, tools and applications (pp. 1255-1275). Hersey, USA: IGI Global.

Steinfield, C., Ellison, N., \& Lampe, C. (2008). Social capital, self-esteem, and use of online social network sites: A longitudinal analysis. J. of App. Dev. Psy, 29(6), 434-445.

Topcu, S., \& Leana-Tascilar, M. Z. (2018). The role of motivation and self-esteem in the academic achievement of Turkish gifted students. Gifted Edu. Int., 34(1), 3-18.

Veenhoven, R. (1996). Happy life-expectancy. Social indicators research. 39:1-58. Retrieved from https://personal.eur.n1/veenhoven/Pub1990s/96b-full.pdf. 
Zywica, J., \& Danowski, J. (2008). The faces of facebookers: Investigating social enhancement social compensation hypothesis; Predicting Facebook TM and offline popularity from sociability and self-Esteem, and mapping the meanings of popularity with semantic networks. Journal of Computer-Mediated Communication, 14, 1-34.

Şahin, C. (2017). The predictive level of social media addiction for life satisfaction: A study on university students. Turkish Online J. of Edu. Tec.-TOJET, 16(4), 120-125.

Romero, L. S., \& Gonzalez, A. M. (2016). High school student trust: Race makes a difference. AERA Online Paper Repository, Paper presented at the Annual Meeting of the American Educational Research Association, Washington, DC. 